Int. J. Electrochem. Sci., 15 (2020) 10289 - 10303

International Journal of

ELECTROCHEMICAL

SCIENCE

$\underline{\text { WWW.electrochemsci.org }}$

\title{
Inhibition Potentials and Adsorption Performance of Two Sulfonylurea Antibiotic Expired Drugs on the Corrosion of Mild Steel in $0.5 \mathrm{M} \mathrm{H}_{2} \mathrm{SO}_{4}$
}

\author{
M. Abdallah ${ }^{1,2, *}$, A. Fawzy $y^{1,3}$, M. Alfakeer ${ }^{4}$ \\ ${ }^{1}$ Chemistry Department, Faculty of Applied Science, Umm Al-Qura University, Makkah, Saudi Arabia \\ ${ }^{2}$ Chemistry Department, Faculty of Science, Benha University, Benha, Egypt \\ ${ }^{3}$ Chemistry Department, Faculty of Science, Assiut University, Assiut, Egypt \\ ${ }^{4}$ Chemistry Department, Faculty of Science, Princess Nourah bint Abdulrahman University, Riyadh, \\ Saudi Arabia \\ *E-mail: metwally555@yahoo.com
}

doi: $10.20964 / 2020.10 .37$

Received: 19 June 2020 / Accepted: 9 August 2020 / Published: 31 August 2020

The inhibition potentials of expired glibenclamide (Glib) and glimepiride (Glim) as two significant sulfonylurea antibiotic drugs on the corrosion behavior of mild steel in $0.5 \mathrm{M}$ sulfuric acid solution were explored using different chemical and electrochemical ways. As the concentration of the expired drugs increases, the weight loss, corrosion current density and the capacity of double layer decrease while the values of charge transfer resistance, surface coverage and the percentage inhibition efficiency augment, indicating that the inhibitory impact of both expired Glib and Glim. The percentage inhibition efficiency increases with decrease in temperature. The inhibition was interpreted by the spontaneous adsorption of the two expired drugs on the mild steel surface by increasing the number of adsorbed particles that cover the largest area of the metal by constructing a barrier layer between the steel surface and the corrosive acid solution. The adsorption process is subject to Langmuir isotherm. Potentiodynamic polarization data demonstrate that both expired drugs act as mixed inhibitors. The activation and adsorption thermodynamic parameters were evaluated and suggest the physical adsorption of the examined drugs

Keywords: Expired sulfonylurea drugs, mild steel, corrosion inhibitors, $\mathrm{H}_{2} \mathrm{SO}_{4}$, adsorption.

\section{FULL TEXT}

(C) 2020 The Authors. Published by ESG (www.electrochemsci.org). This article is an open access article distributed under the terms and conditions of the Creative Commons Attribution license (http://creativecommons.org/licenses/by/4.0/). 